\title{
Negociando com os leitores: o "novo" e o "antigo" homem nos editoriais da revista Men's Health*
}

\author{
Cláudia Regina Ribeiro** \\ Jane Russo ${ }^{* * *}$
}

\section{Resumo}

Este artigo, norteado pelos conceitos de gênero, masculinidades e sexualidade, analisa os discursos de editoriais da revista Men's Health. Identificamos nesses discursos marcas claras de valorização e defesa de novas formas de ser masculino e uma flagrante desvalorização do que chamamos de masculinidade tradicional. Consideramos que essas marcas revelam a necessidade de convencimento dos leitores, ou uma negociação de sentidos, para que esses homens adotem os padrões sugeridos pela revista sem o temor de colocarem em dúvida a sua heterossexualidade.

Palavras-chave: Masculinidades, Sexualidade, Novo homem, Revista Men's Health.

\footnotetext{
* Recebido para publicação em 9 de janeiro de 2013, aceito em 18 de março de 2013. Este artigo originou-se da pesquisa "Sexualidade, corpo e saúde masculinos: transformações e permanências nos discursos de homens e da revista Men's Health", desenvolvida durante o curso de doutorado no Programa de Pósgraduação em Saúde Coletiva, da Universidade do Estado do Rio de Janeiro (IMS/UERJ). Agradeço à CAPES pela bolsa de estágio de Doutorado PDEE e ao Prof. Dr. Miguel Vale de Almeida, pela coorientação durante a bolsa.

*** Instituto de Medicina Social, UERJ. 13cribeiro@gmail.com

*** Professora associada do Programa de Pós-Graduação em Saúde Coletiva do Instituto de Medicina Social, UERJ. jane.russo@gmail.com
} 
478 Negociando com os leitores

Dealing with Readers: The "New" and "Old" Man in the Editorial of the Magazine Men's Health

\begin{abstract}
This paper, guided by the concepts of gender, masculinity and sexuality, examines the discourses from editorial magazine Men's Health. We identify these discourses clear marks of appreciation and defense of new ways of being male and a blatant devaluation of what we call traditional masculinity. We believe that these marks show the need to convince the readers, or a negotiation of meanings, for these men to adopt the standards suggested by the magazine without the fear of putting in doubt his heterosexuality.
\end{abstract}

Key Words: Masculinities, Sexuality, New man, Men's Health Magazine. 


\section{Introdução}

No final da década de 1990, desponta no cenário midiático nacional a figura do "novo homem". Esse novo modelo de masculinidade projeta-se como um "avanço" ao assumir mudanças em certos valores e crenças típicos da masculinidade que nesse trabalho chamaremos de tradicional. ${ }^{1}$ Para que o "antigo homem" se transformasse em um "novo homem", a receita divulgada pela mídia era simples: ele deveria ter mais cuidados com a pele, os cabelos, o vestuário, e afrouxar o estilo "machão". Tudo isso sem se aproximar da homossexualidade, aspecto fundamental para a aceitação e a adesão a essas mudanças. É verdade que a ideia de que os homens deveriam também empreender mudanças de comportamento nos universos doméstico e familiar foi ventilada na mídia, mas não com a mesma força.

Ratificando essa tendência midiática de divulgar um novo padrão de masculinidade, em maio de 2006 foi lançada no Brasil a revista Men's Health, que já circula nos Estados Unidos desde 1987. Essa publicação distingue-se das demais revistas para o público masculino heterossexual por abordar temas até então reconhecidos como mais próprios às mulheres $e$ aos homossexuais, como sexualidade, cuidados com a saúde e a estética, estilo, moda, comportamento social etc. Ela se dirige aos homens heterossexuais, das classes média e alta urbanas, e formação de nível superior - um público "altamente qualificado, extremamente bem informado, de alto nível socioeconômico",

1 Usamos a categoria "masculinidade tradicional" em contraposição à "nova masculinidade" ou "novo homem". Trata-se de uma referência feita por Connell (1995) acerca da masculinidade produzida no mundo moderno, portanto, historicamente recente, atrelada à ideia de permanência e não de transitoriedade como é próprio do gênero, e que se relaciona à família tradicional. Com essa categoria, procuramos dar conta da ideia de um homem que tem bastante preocupação com relação à manutenção de alguns valores centrais da masculinidade dominante em nossa cultura. 
como afirmou seu editor. ${ }^{2}$ Embora a alimentação, os esportes, os cuidados de saúde etc., sejam, em sua maior parte, temas abordados na revista, os temas centrais são o fitness e o embelezamento, a modelagem e a maximização dos usos do corpo que levarão aos ganhos profissionais, sociais e sexuais. $\mathrm{Ou}$ seja, como se observa também nas revistas femininas mais modernas, as fronteiras entre a saúde e o bem-estar, de um lado, e o cuidado estético com o corpo, de outro, são bastante tênues.

Do nosso ponto de vista, a revista vem apresentando um modelo de masculinidade que em alguns aspectos pode ser considerado como "novo", mas que ainda apresenta fortes características da masculinidade tradicional. No entanto, para apresentar e valorizar o seu modelo de "novo homem", ela lança mão de duras críticas ao "antigo", desqualificando-o; contradição que, acreditamos, se configura como uma estratégia de aproximação com os leitores que podem ainda ter dúvidas sobre as vantagens das transformações que a Men's Health sugere em seu modo de ser masculino.

Com relação à escolha dos textos para a análise, argumentamos que as edições brasileiras muitas vezes publicam matérias traduzidas de outros países, inclusive com as mesmas fotografias. Isso significa que os temas $e$ as abordagens das matérias são tomados como interessantes para homens de muitos países, assim como o modelo corporal exposto pelas fotografias é tomado como universal. No entanto, os editoriais são textos originais produzidos em nosso país e direcionados especialmente para o público brasileiro. Nesse sentido, consideramos que esses textos podem ser tomados como locus privilegiados, onde pode ser percebido qual o modelo de masculinidade presente em nossa cultura que vem sendo evocado como passível de crítica. E qual o modelo que deve substituí-lo com mais sucesso.

\footnotetext{
2 O editor, o jornalista Airton Seligman, foi entrevistado em novembro de 2008 na sede da Editora Abril em São Paulo. A entrevista foi concedida mediante assinatura de Termo de Consentimento Livre e Esclarecido aprovado pelo Comitê de Ética do Instituto de Medicina Social IMS/UERJ. Pela particularidade do entrevistado, o termo nos permite divulgar o seu nome.
} 
Apresentamos uma apreciação crítica de 16 editoriais da revista: oito de 2008 e oito de $2009 .^{3}$ Além do que foi dito, esses editoriais foram escolhidos porque apresentam certas regularidades discursivas no que diz respeito à "nova" masculinidade, que a revista apresenta e defende, e à "antiga", que desqualifica. Discursos reveladores da construção de novas verdades, ou normas, sobre o que é ser masculino, que deverão ser adotadas pelas camadas médias e altas da sociedade.

\section{Pressupostos teóricos metodológicos}

Começamos por definir masculinidade(s) como sendo "uma configuração de práticas em torno da posição dos homens na estrutura das relações de gênero" (Connell, 1995:188). Raewyn Connell ${ }^{4}$ conclui sua definição afirmando que as formas de masculinidades são complexas e contraditórias, e que essa contradição diz respeito à própria dinâmica de gênero, não sendo masculinidade um caráter apenas dos homens.

Assumir o uso do termo no plural - masculinidades significa admitir a ideia de diversidade de formas de ser masculino e que "masculinidades significam diferentes coisas para diferentes grupos de homens em diferentes momentos" (Kimmel, 1998:106). Existem muitas formas de ser homem e masculino dentro de uma mesma sociedade em um mesmo período histórico. No entanto, cada sociedade em cada momento constrói um modelo hegemônico de masculinidade, que se constitui como um padrão cultural ideal pelo qual todos os homens se medem. Esse modelo é construído a partir de narrativas presentes na cultura que informam como os homens devem ser, como se comportar, do que devem gostar, do que se aproximar ou se afastar, tendo como referência as mulheres. Narrativas que pressionam meninos $e$

\footnotetext{
3 Janeiro, fevereiro, abril, maio, junho, setembro, outubro e novembro de 2008. E janeiro, fevereiro, março, maio, junho, agosto, setembro e outubro de 2009.

${ }^{4}$ Desde 2007, o sociólogo Robert Connell assume o nome Raewyn Connell. No entanto, os artigos citados foram assinados com o nome masculino, e assim estarão nas referências.
} 
rapazes a agirem $e$ a sentirem de acordo com essas condutas (Connell, 1995).

A existência de um modelo hegemônico ou dominante de masculinidade pressupõe a existência de outras formas de ser masculino que destoam da hegemônica. Essas formas vêm sendo chamadas de subalternas ou marginais, e, na lógica da construção de gênero masculino e do modelo de masculinidade, têm como uma das funções a de ratificar, por oposição, o modelo dominante. Se ser heterossexual é o pressuposto primeiro da masculinidade hegemônica, ser homossexual é o que caracteriza primeiramente a masculinidade subalterna (Kimmel,1997). Mas essa tensão não se manifesta apenas no que tange à orientação sexual ou às posições heterossexuais-homossexuais, mas também no que diz respeito às características de classe, raça-etnia, idade, formação e profissão, por exemplo. Produzem-se assim diferenças que se manifestam como relações de poder, de hierarquia e subordinação entre os homens e entre os homens e as mulheres (Connell, 1995; Heilborn e Carrara, 1998; Kimmel, 1998). Tudo que foi apresentado nos remete à ideia de que as normas de gênero são fluidas e estão submetidas, também, às práticas e necessidades do cotidiano, sendo colocadas em jogo, ou de lado, sempre que se faz necessário. É senso comum afirmarmos que os homens e o universo masculino vêm mudando nas últimas décadas e que tais mudanças vêm se dando em decorrência das transformações nas relações de gênero e de trabalho, impulsionadas, sobretudo, pelos movimentos feministas e $\mathrm{LGBT}^{5}$ e pelas transformações econômicas e sociais trazidas pelos avanços do capitalismo (Nolasco, 1993; Connell, 1995, 2005; Kimmel e Kaufman, 1995 - entre outros/as).

No bojo de tais transformações, é necessário considerar a participação dos meios de comunicação - a mídia - como produtores e divulgadores de mudanças sociais, inclusive novos padrões de masculinidade e de feminilidade. Não é possível ignorar que a mídia exerce um forte poder na formação dos sujeitos no sentido de construir e desconstruir olhares, gostos,

5 Sigla referente a Lésbicas, Gays, Bissexuais, Travestis e Transexuais. 
formas de ser e de se apresentar no mundo, sendo notória, nos últimos tempos, sua atuação como divulgadora de novas verdades sobre ser mulher, homem, criança, idoso/a, saudável, bonito/a etc. (Medrado, 2000; Thompson, 2002). Aspectos que dizem respeito especialmente a este trabalho.

Uma rápida leitura de qualquer edição da Men's Health já nos possibilita perceber que o que está sendo proposto para o homem contemporâneo é a reformulação de algumas crenças acerca das masculinidades que dizem respeito, sobretudo, ao corpo. Essa reformulação pressupõe investimentos na conformação dos seus corpos que, por sua vez, requerem muita disciplina e autocontrole. O conceito de poder disciplinar de Michel Foucault torna-se, por isso, fundamental para nossa análise. Segundo Foucault (1977), o poder disciplinar incide sobre o corpo, ou, de forma mais ampla, em seu disciplinamento $e$ controle, sobretudo no que diz respeito à sexualidade, tendo seu exercício íntima relação com o sistema social e econômico que surge no final do século XVIII. Trata-se de um tipo de poder que investe sobre o corpo vivo, gerindo e distribuindo suas forças, numa relação de "docilidade-utilidade", aspectos indispensáveis naquele momento para a consolidação do novo sistema econômico (Foucault, 1997). Ao contrário do "poder soberano" típico do Antigo Regime, esse novo exercício de poder, em vez de apenas "dizer não", produz desejos, "induz ao prazer, forma saber, produz discurso. Deve-se considerá-lo como uma rede produtiva que atravessa todo o corpo social muito mais do que uma instância negativa que tem por função reprimir" (Foucault, 1993:8).

A ideia de produção do, ou incitação, ao desejo é, sem dúvida, fundamental quando se discute o papel da mídia no mundo contemporâneo. De fato, o estágio atual do capitalismo, a sociedade de consumo, tem a mídia como elemento essencial que cumpre o papel de anunciar as novidades e associá-las aos grupos e pessoas, imputando valores às mercadorias, que estão muito além do econômico, contribuindo para a produção de um mercado consumidor cada vez mais ampliado (Baudrillard, 1976; Bauman, 2005; Douglas; Isherwood, 2009). 
Segundo Colin Campbell (1995), o consumo não se esgota na efetiva compra de objetos materiais, tendo um caráter mais "espiritual" ou simbólico, já que a busca é pela realização de uma fantasia acerca de si mesmo. No mundo capitalista do consumo, consome-se o sonho de ser um certo tipo de pessoa. O sonho, a fantasia e o consumo vão caracterizar, como sabemos, o universo feminino. $\mathrm{O}$ corpo feminino se constituiu tradicionalmente como objeto de um sem número de intervenções médicas $e$, com o tempo, também de intervenções estéticas e reparadoras (Hubbard, 1990; Fausto-Sterling, 2002; Schiebinger, 1987). A inclusão dos homens nesse mercado de "aprimoramento" ou embelezamento do corpo é uma importante estratégia que visa transformar o homem em consumidor não apenas do corpo feminino, mas também do corpo masculino "trabalhado"/"aprimorado"/ embelezado, como um corpo que pode e deve ser o seu. Trata-se, portanto, de aproximar o homem do universo feminino, fazê-lo desejar ter um certo corpo masculino sem que isso signifique ser homossexual. O homem deve ser ensinado a ver seu corpo como objeto de investimento e cuidado e, também, de sonho e fantasia (o que sustenta o consumo). Ou seja, de fato o que se busca é uma "feminização" do macho tradicional. Nossa questão é: qual o significado dessa "feminização" e o quanto isso implica em termos de negociação com a masculinidade tradicional.

Vamos argumentar que essa "feminização" proposta pela Men's Health através da incitação a um certo consumo masculino não implica na problematização de fato da desigualdade de gênero e questionamentos correlatos. Ao contrário, a ênfase no cuidado corporal, na estética e no cuidado de si, se de algum modo aproximam o "novo homem" do universo feminino, por outro reforçam um conjunto de estereótipos de gênero, como procuraremos demonstrar no decorrer de nossa análise.

\section{Cartas do Editor: negociando com os homens}

Por definição, os editoriais são textos opinativos - a voz da empresa, do editor e/ou da equipe de redação ou de algum/a 
colaborador/a -, não tendo a obrigação de respeitar as regras da redação jornalística, como a imparcialidade. No caso da revista Men's Health, o editorial é chamado de Carta do Editor. Esse título, acreditamos, ajuda a aproximar quem escreve de quem lê esses textos, possibilitando um grau de informalidade e o "tom de conversa" que percebemos neles. As Cartas são curtas, apresentam o tema central da edição, exprimem a visão da revista sobre os temas e indicam as matérias em que o leitor encontrará esses assuntos.

No que diz respeito à construção textual, nos editoriais, o enunciador e o destinatário estão presentes nos textos - editor $e$ leitor da revista. O editor se coloca ora apresentando o conteúdo da edição ora elencando as qualidades da revista em um texto curto, cerca de meia lauda, distribuído em duas colunas. A linguagem usada é bastante informal, buscando aproximar-se dos leitores - homens -, tomando como frequência os recursos da ironia e do humor e lançando mão de palavras e expressões do cotidiano. A foto do editor em meio corpo e quase sorrindo colabora para que se forje uma atmosfera de conversa. Os textos têm um tom de aconselhamento, não sendo frequente o uso do imperativo, embora ele também seja usado. $\mathrm{O}$ enunciador dirigese ao homem das classes médias e altas e a alguém que, por estar lendo a revista, encontra-se no caminho da mudança e já adotou alguns novos hábitos. Esse homem é sempre elogiado $e$ estimulado a continuar nesse percurso, a aprender e se informar mais através da revista e, se possível, a influenciar os amigos para também mudarem. São discursos que enaltecem o leitor, mas também a publicação. Todos os editoriais trazem um "olho" 6 que tem a função de destacar a ideia síntese do texto. No mês de maio de 2008, aniversário de dois anos da revista, a foto mostrava toda a equipe de redação sorrindo, uma imagem que demonstrava descontração e unidade no grupo. ${ }^{7}$

${ }^{6}$ No jargão jornalístico, olho é um trecho do texto destacado no corpo do próprio texto. É usado para chamar a atenção para uma ideia.

7 Em 2009, o editorial da edição de aniversário trouxe somente a foto do editor. 
Essa informalidade sempre nos chamou a atenção, uma vez que muitas expressões poderiam ser classificadas como pouco próprias para um editorial, sobretudo se o público alvo é constituído por homens das classes A e B. Mas percebemos muito rapidamente que essa linguagem é muito "apropriada" para uma conversa informal, quando não se leva em conta a distinção de classe, mas de gênero: um "papo entre homens". Também é perceptível que o editor busca aproximar-se do leitor ao incluir-se, ou à equipe, nas questões tratadas, trazendo a ideia de que, sendo também homem - e bem sucedido, na mesma faixa etária de muitos leitores, morador de São Paulo etc. -, os problemas, dúvidas ou características do leitor também podem ser as dele ou dos membros de sua equipe, criando um vínculo entre ele e o seu público. Mas, nessa conversa entre homens, só quem tem a palavra é o editor que apresenta a edição, elogia as matérias, valoriza os temas e convida à leitura.

De modo geral, entre as marcas da nova masculinidade percebemos a ênfase na sexualidade e a supervalorização do trabalho, que também são marcas claras da masculinidade tradicional, revelando a vinculação entre os dois modelos. A negociação entre eles se faz, como veremos adiante, através da articulação entre o trabalho e a sexualidade, como elementos fundadores e justificadores, e a necessidade de cuidado com a aparência e o corpo.

Priorizaremos a ordem cronológica de publicação da revista, que será vez por outra alterada para uma ordem temática, como deixaremos claro mais adiante. Optamos ainda pelo uso do itálico sublinhar nas frases, palavras ou expressões que serão tomadas de forma mais importante em nossa análise.

Começamos pelos editoriais de janeiro e fevereiro de 2008. As matérias e os textos convocam os leitores a obterem sucesso profissional no ano que se inicia, e os conselhos são: manterem-se bem informados, cuidar da aparência e da saúde. Respectivamente, os títulos são os seguintes: "Mate 2008 no peito" e "Pronto para o sucesso?". Já no primeiro parágrafo do editorial de janeiro, temos: 
Drogas, Aids, muitas formas de obesidade, males do coração, estresse e até mesmo câncer são doenças implacáveis, riscos reais com os quais nos defrontamos dia a dia, mas que poderiam ser evitados com um mínimo de informação [...]. Saber mais não é só uma questão de ganhar diferencial competitivo na selvageria do mundo corporativo. Saber é um instrumento de sobrevivência real, física. Um instrumento de autoconhecimento (e, portanto de bem-estar), uma alavanca na conquista da qualidade de vida. E, sim, uma arma na busca_da mulher ideal, a mola mestra do motor de uma vida mais longeva [...].

O editorial de fevereiro avisa que a revista traz inúmeras estratégias para o campo do trabalho:

[...] desde um guia de autogestão para você se livrar dos pepinos até os looks para você chegar arrasando - na reunião com o chefe ou no café com a colega lindona. $\mathrm{O}$ que queremos é ver você cheio de energia, pronto para mais um ano legal - por isso essa Edição Especial Fitness (Na boa, ter um corpo em cima abre muitas portas para o sucessol [...]. Curtiu a edição? Nossa missão é essa mesma: dar muita informação saborosa e relevante para você ter uma vida mais leve, mais divertida, mais saudável e com mais conquistas - no campo profissional e sexual.

Os dois editoriais trazem a ideia central da revista que, diferentemente do que o seu título indica, não é saúde, mas o corpo, embora sejam dois temas indissociáveis. É o corpo saudável $e$ bonito, nos moldes do que a revista recomenda $e$ ensina a obter, que abrirá as portas de sucesso profissional $e$ sexual/amoroso para o leitor. A Men's Health é a encarregada de instruir o novo homem, mas é ele o agente da transformação, o que deve começar a atuar logo nos primeiros dias do ano para ter uma vida mais saudável, mais divertida e plena de conquistas. Essas são ideias importantes que atravessam outros editoriais, estão presentes em todas as edições da revista e fazem parte dos 
discursos da mídia e da Medicina hoje (Fraga, 2005; Palma, 2009; Marshall, 2006). São também ideias que podem ser encontradas nos discursos das empresas e dos esportes profissionais: empreendedorismo, pró-atividade, gestão, superação de obstáculos, vitória, conquistas; e que, por isso, podem encontrar eco junto aos leitores projetados da revista. Lembramos aqui Connell (2005), segundo a qual, essa esfera social/profissional vem se constituindo como importante sinalizador da masculinidade contemporânea.

O editorial de janeiro faz um alerta sobre os males dos tempos modernos - males que a mídia impressa e televisiva vem destacando nos últimos tempos - $e$ as dicas sobre como evitá-los, convocando os homens a cuidarem da saúde começando pela obtenção de informações. Informar-se e cuidar da saúde, aspectos até então pouco relacionados ao universo masculino, ganham uma nova dimensão e não representam mais o perigo de aproximação com o universo feminino, quando são associados à ideia de vitória e ganhos, sobretudo profissionais e sexuais. Para confirmar que se cuidar nada tem a ver com o feminino, o título do editorial "Mate 2008 no peito" faz uma analogia ao futebol, um esporte tipicamente masculino e que mobiliza bastante os brasileiros, numa aproximação com o mundo dos homens heterossexuais.

Esse título traz também uma metáfora bélica, presente ainda no subtítulo "Saiba mais e desarme as bombas-relógio do seu futuro", e nos faz pensar em violência, outro elemento intimamente relacionados à masculinidade em nossa cultura. $\mathrm{O}$ uso das palavras "mate", "ganhe", "detone", "tática", "plano de ação" e "sobrevivência", que fazem parte do repertório belicista e dos esportes, são comuns nos slogans publicitários há muitas décadas, utilizados como estratégias para relacionar um certo produto ao universo masculino (Veríssimo, 2008). Na Men's Health, palavras e expressões desse tipo estão presentes não somente nos editoriais, mas também em capas e títulos das matérias e, acreditamos, são empregadas para relacionar o homem moderno à imagem de lutador e vencedor, que também evoca a 
masculinidade, convocando-o para as mudanças que precisam ser feitas, principalmente, no corpo. Um jogo entre discursos produzidos para o "novo" homem permeado por metáforas e palavras costumeiramente utilizadas pela publicidade para atrair o homem tradicional.

É sabido que a associação entre as ideias de lutador $e$ masculinidade é um elemento importante da construção do ethos masculino, na medida em que a prática desportiva agrega aspectos simbolicamente associados ao gênero, como conquista, agressividade, conflito e uma disposição "natural" para o confronto (Cecchetto, 2009). Valores como força física, coragem e destemor são tipicamente atrelados à masculinidade dominante. ${ }^{8}$ Nesse caso, as metáforas de guerra nos remetem também à ideia de violência que, segundo Sócrates Nolasco (2001) é uma das formas de sociabilidade masculina, tornando-se elemento importante na construção de sua subjetividade.

No caso dos editoriais e suas metáforas bélicas ou esportivas, é interessante identificar quem ou o que está sendo eleito como inimigo desse homem e desse corpo. E compreender, a partir do que nos mostra Fátima Cecchetto (2009), que tipo de masculinidade está sendo interpelada por essas metáforas e quais os objetivos dessa luta ou porque se luta. Nos editoriais destacados, os inimigos são as drogas, a obesidade, a "pança", o amigo mala, a TPM da parceira e os amigos trogloditas que não se curvaram às mudanças e criticam os que mudaram, entre muitos outros "problemas" que o novo homem precisa "driblar" para ter mais saúde, beleza e bem-estar.

8 O historiador da cultura, George Mosse (1996), em estudo acerca da criação da imagem de masculinidade normativa na Europa no final do século XVIII, afirma que o ideal de corpo construído naquele momento - musculoso, rígido, forte - baseado no corpo grego e nas ideias de coragem, honra, força $e$ virilidade, se tornou um padrão, um modelo a ser seguido. Afirma ainda que a criação daquele estereótipo, que ainda é o aceito hoje como sendo a materialidade daquelas qualidades, foi orquestrada pela filosofia positivista, Medicina e burguesia. Um corpo que não era dado, mas que precisava ser produzido através de exercícios físicos. E que atuava como um modelo e que também definia o contra-estereótipo, o marginalizado. 
É flagrante ainda, nos editoriais e na revista, a insistência na ideia de que ter um corpo bonito e saudável depende unicamente do esforço pessoal, um discurso que tem seu cerne na disciplina $e$ no controle sobre o corpo. Nesse sentido, o inimigo é o sedentarismo, a preguiça e os hábitos alimentares considerados incorretos dos quais o homem moderno precisa se livrar. $\mathrm{O}$ estereótipo masculino construído por esses textos traz como marca a ênfase na sexualidade/virilidade, no vigor físico, a valorização do trabalho e da profissão, da inteligência, da racionalidade. Ou seja, a adoção de novos comportamentos (o cuidado com o corpo) se justifica a partir de uma concepção tradicional do masculino.

Mas, a relação entre o homem tradicional e o moderno, nos editoriais, se dá mais fortemente a partir do mundo do trabalho, importante para ambos e trazido com ênfase nos dois textos. A ideia de sucesso profissional, por sua vez, está intimamente relacionada com o corpo bonito, bem cuidado e saudável, nos moldes da revista, pois esse é o corpo que "abre portas", que agrada de modo geral. Interessante notar que o homem descrito nos dois editoriais é um homem que trabalha em um escritório, talvez um executivo, que tem reuniões com "o" chefe, um homem que é convocado para compartilhar decisões, que já tem algum sucesso profissional e precisa mantê-lo ou aumentá-lo, perfil que mais uma vez nos lembra o que apontou Connell (2005) como sendo o modelo masculino valorizado atualmente. Mas nas duas edições silenciam sobre o fato de que um homem que precisa se esforçar para ter sucesso profissional dificilmente terá tempo livre para cuidar do corpo "como deve". Esse impasse é "resolvido" em outros editoriais, que trazem a ideia de disciplina e serão analisados mais adiante.

Vale a pena lembrar que o trabalho é fundamental para a caracterização da masculinidade e que é através da atividade profissional - que deve se efetivar preferencialmente na esfera pública - e do que provém dela - recursos financeiros e status, sobretudo - que os homens encontram elementos para garantir segurança para si e para sua família e para reforçar sua autonomia e autoridade diante dos demais (Nolasco, 1993, Almeida, 2000, 
Olivarría, 1999, Goldenberg, 2005). Essa importância do trabalho como constitutivo do mundo masculino, mescla-se à noção que separa os universos privado/feminino e público/masculino, estando o segundo binômio carregado de positividade (Bourdieu, 2003). No caso dos homens a quem os editoriais se dirigem, o trabalho não se relaciona com o esforço braçal, mas intelectual que, além dos ganhos financeiros, confere status social a eles. É interessante notar ainda que o sexo precisa ser trazido ao discurso, não importando o teor da conversa. Vemos que mesmo quando o tema é o trabalho, as questões sexuais não ficam de fora.

Nos demais editoriais de 2008, também identificamos muito claramente algumas das marcas discursivas descritas anteriormente. O título do editorial de abril é "O essencial e o supérfluo" e nele lemos o seguinte:

Você, leitor, já sabe que a Men's Health é uma revista que funciona, que é para ser usada mesmo, manipulada, carregada na mochila, de casa para a academia, da banca para o café na padaria, para o parque... [...] queremos agora fazer nossos amigos mais blasés - aqueles que vivem apertando a tecla F - "usarem" a Men's Health. Os caras até dão uma folheada, mas, lá no meio da happy hour, soltam essa: 'Não tenho tempo pra ficar malhando três horas por dia'. Ou resmungam, sobre a bela matéria de nutrição da última edição: "Tentar equilibrar o que você come é coisa de mauricinho" [...]. Não imaginam que não custa nada ter um pouco de disciplina e que ela é a matéria-prima do homem contemporâneo. Ou seja, com um mínimo de informação e organização, você controla legal sua alimentação sem deixar os prazeres de lado. Foi para fazer um contraponto a essa galera - $e$ ao bonde errado da história em que eles se encontram - que citei você, leitor.

O olho do editorial traz o texto: "Informação e disciplina nos levam longe e não tiram o prazer da viagem".

O editorial de maio, edição de dois anos da revista, traz o título: "Valeu, seu exigente!" O texto afirma que o leitor é um 
sujeito que tem um "estilo exigente" que "faz parte de um dos grupos mais qualificados entre os leitores de revistas do Brasil" $e$ que foi para esse público que a Men's Health foi lançada:

Sabíamos que existia um público top, bem informado, ávido por informações sobre qualidade de vida. Mas também queríamos passar um tipo de informação moderna, que não fosse chata nem careta, que contemplasse sexo de forma legal, que abordasse condicionamento físico sem obsessão, saúde sem neuras, nutrição sem cartilhas radicais, moda sem vitimar o usuário, que falasse de carreira para ganhar grana etc. E aí encontramos você.

Afirma ainda que a revista está sempre buscando alinhar suas matérias ao estilo "divertido, esperto, instigante, surpreendente, sedutor, curioso..." do leitor e que nela ele poderá encontrar um guia completo para ajudá-lo a expressar "suas qualidades - elegância, inteligência, bom gosto - $e$ facilite sua vida na hora de turbinar a carreira, seduzir a colega lindona, se sentir confortável e em sintonia com as últimas tendências...".

No editorial de junho, "Conserte seu amigo mala", lemos o seguinte:

Tenho um amigo que sempre me provoca quando falamos da Men's Health. Bem, o cara é um mala. Quando lançamos a revista, há dois anos, "o problema" dele era a capa. Hoje, já se acostumou à imagem de homens em vez de mulheres. "Tá legal, não tira pedaço", diz. Depois foi o destaque dado aos treinos de condicionamento físico. Para ele, havia "coisa mais importante a fazer nas horas vagas", como ir ao cinema, ler um livro... "Prefiro malhar o cérebro", dizia. Mais tarde, encanou com nossas dicas de higiene e beleza -"Peraí, meu chapa, passar creminho é demais!". Meu amigo é um mala, mas amigos a gente tem de aguentar. E fazer tudo para ajudá-lo.

No editorial de setembro, intitulado: "Tchau, caverna", podemos ler: 
[...] O homem contemporâneo [...] está deixando para trás as pegadas do brucutu pré-histórico e se voltando "para dentro", se "interiorizando". Isso tanto no que diz respeito a suas emoções quanto ao seu habitat. Em busca de equilíbrio e bem-estar - seu e de sua família -, ele passa mais tempo com a mulher, com os filhos, com os seus livros e CDs, com sua coleção de arte ou de ferramentas, na frente do home theater, jogando videogame ou assistindo ao futebol com amigos. Para os solteiros, o lar vem assumindo um papel ainda mais radical: virou uma arma de sedução. Não mais um simples abatedouro, a bat-caverna com o colchão no chão e uma cerveja na geladeira, mas uma espécie de extensão da personalidade do homem, onde ele mostra seu estilo, sua identidade. Sim, para quem busca sucesso na vida e na carreira, o lar funciona como um trampolim.

\section{Em outubro, "Confie no seu talco":}

Seu nécessaire é maior do que o da sua namorada?" Essa era a brincadeira feita entre os homens há quase uma década atrás, quando a indústria dos cosméticos começou a jogar seus anzóis para o nosso lado. A piada, óbvio, era pura provocação intimidatória: vinha sempre do_machão, o cara à prova de creminhos. Natural que, mesmo na virada do século 20 para o 21, a tribo do tacape estivesse forte, unida. Os homens vinham tentando se recuperar da porrada que a sua auto-estima sofreu com a ascensão das mulheres na sociedade [...] reforçar novos pilares brucutus foi só a resposta mais rápida e infantil que achamos para recauchutar o ego. E aí, mudou algo nesses dez anos? Sim, mudamos, e este é um movimento também... natural. Até o mais empedernido machão daquele final dos anos 90 tem hoje seu creminho escondido. Ou usa os cosméticos da mulher/namorada para se livrar da "culpa" - da mesma forma que o cara que só fila cigarro e diz que não fuma. [...]

É que dada a natureza intimidatória do clube do bolinha universal, apostar na sua imagem também realça sua 
ousadia, pró-atividade, criatividade - e esses são valores simpáticos aos caras que vão abrir as portas para o seu sucesso. Tenha isso sempre em mente ao ouvir provocações sobre o tamanho do seu nécessaire. E imagine quantas portas seus amigos piadistas conseguem abrir com o tacape deles.

No olho, lê-se: "Cuidar da aparência é uma jogada bem prática, portanto masculina".

$\mathrm{O}$ editorial de novembro continua reforçando as qualidades do novo homem, mas lança uma ideia nova, a de "estilo" e, por isso, será analisado juntamente com outros editoriais de 2009, pois percebemos que esse tema foi tratado de forma mais importante nos editoriais daquele ano.

São muitas as possibilidades de análise desses textos, mas elegemos apenas algumas. Primeiramente voltamos à ideia de negociação entre a revista/editor $e$ os homens $e$ nosso questionamento da real possibilidade de aceitação das mudanças por parte dos homens. Esses editoriais nos levam a acreditar que mesmo os homens que se propõem a ler a revista $e$, provavelmente, já estejam inclinados às mudanças que ela sugere, ainda precisam ser estimulados a continuar nesse caminho, e os editoriais têm o papel de insuflá-los a não desistir. E mudar significa também assumir com orgulho essa nova forma de ser homem, sendo a revista um estandarte a ser levado como prova dessa coragem e necessidade de mudar.

Entre os argumentos utilizados para a adoção ou manutenção das mudanças está a ideia de que vivemos em um tempo em que se espera muito mais de um homem do que ser provedor, bom pai, bom marido e bom profissional. Ou melhor, para ser tudo isso, hoje, ele deve antes construir um corpo bonito e saudável, ter estilo e estar bem informado, reconhecer a necessidade de cuidar da saúde e da estética, rompendo com valores antigos da masculinidade. Ele precisa fazer exercícios para ganhar músculos e perder a barriga, cuidar da pele com cremes e se depilar, entender de cuidados domésticos e culinária, saber 
como seduzir a mulher moderna, dar mais prazer a ela para conseguir fazer muito sexo, entre tantos outros ensinamentos que esse homem tem que adquirir e que podem ser encontrados nas páginas da Men's Health.

Pode-se perceber ainda nesses editoriais que a masculinidade tradicional é tanto refutada e ridicularizada quanto muitas vezes insuflada. Ora afirmam que os homens devem mudar e deixar "a caverna", ora reforçam aspectos relacionados à autoridade e à potência, vinculadas à sexualidade e ao trabalho, tão típicos das masculinidades tradicionais. No entanto, os textos silenciam sobre comportamentos como dividir as tarefas domésticas com a mulher e o cuidado com os filhos. Talvez porque a revista seja direcionada ao homem solteiro (apesar da negativa do editor quanto a isso). Quando toca no primeiro assunto, o cuidado com a casa, a revista tende a associar esse cuidado às estratégias para a conquista amorosa, não a uma nova atitude que ressignificaria a relação entre o homem $e$ o mundo $e$ as tarefas domésticas, quase antagônicas ao homem tradicional.

No que diz respeito à sexualidade, o risco da aproximação com a feminilidade ou com a homossexualidade precisa ser afastado dos que se inclinam à adoção dessas mudanças ou a serem leitores da Men's Health. Esses homens precisam de apoio e de argumentos que possam usar contra os mais "reacionários" que desconfiam da sexualidade dos que se modernizam $e$ reforçam a heteronorma, deixando claro para quem a revista se dirige, qual sua orientação sexual. Trocando em miúdos: incluir em sua lista de compras um creme especial pós-barba ou guardanapos "estilosos" para usar no jantar que preparará para os/as amigos/as do escritório ou a namorada (mais provavelmente a garota com quem está saindo e pretende levar para a cama) só vai lhe trazer vantagens profissionais e sexuais, contanto que os/as convidados/as também compartilhem dessas novas verdades. $\mathrm{E}$ mesmo que isso não aconteça no primeiro momento, eles acabarão se dando conta das vantagens de ser um novo homem quando vislumbrarem o sucesso profissional e sexual/amoroso dos "novos" homens. 
Como já argumentamos, as mudanças propostas para esse novo homem não dizem respeito a negociações com relação às relações de gênero, mas ao corpo e à saúde como objetos de consumo. A estratégia da revista, presente nos editoriais, é bastante plausível do ponto de vista do capitalismo contemporâneo, que tem como resultado a ampliação sem limites do mercado consumidor.

Especificando um pouco a análise, podemos dizer que o editorial de abril traz, logo nas primeiras linhas, um tema bastante sensível à publicação. Carregar a revista na mochila e levá-la para ser lida no parque significa assumir algo que para muitos ainda pode ser complicado: ser leitor de uma revista cuja capa traz um homem com o dorso à mostra e que oferece dicas sobre estética, cremes, modas etc. ${ }^{9}$ Esse aspecto de "poder" ser leitor de uma revista que traz tantas fotos de homens sem camisa e fala de temas tipicamente femininos foi explicitado no editorial de junho $e$ referido pelos nossos informantes. Ao que parece, o editor tem ciência da dificuldade que seria levar e manter uma revista nesses moldes em nosso país, e trata de reforçar a autoestima e os argumentos contrários dos leitores para que resistam às investidas dos que ainda não foram convencidos.

Em setembro, o foco foi a casa, um espaço que tradicionalmente não é associado aos homens. A ideia de que esse é o universo por excelência feminino é apontada por autores/as, como Bourdieu (2003), quando se referem aos homens de modo geral, e por Heilborn e Gouveia (1999) e Almeida (2000), quando falam dos homens das classes populares. O último autor, a partir das suas observações de um grupo de homens da aldeia de Pardais (Portugal), nos revela que para aqueles informantes a casa é um espaço feminino que deve ser cuidado e ocupado por elas,

\footnotetext{
9 Todas as capas trazem também fotos de mulheres e algumas mostram um casal. Mas a foto do homem sem camisa é o que mais chama a atenção, pois diferente da foto feminina, bem pequena, ela ocupa a parte central da capa. Essa característica traz desconfiança com relação ao público da revista, como foi constatado durante entrevistas com homens quando da realização da pesquisa que originou este artigo.
} 
não sendo muito apropriado para os homens, pois "estar em casa faz mal, amolece e feminiza o homem" (Almeida, 2000:64):

As classes médias vêm tomando um caminho diferente valorizando as mudanças masculinas nesta área e, embora nem sempre os discursos se tornem práticas efetivas, cuidar da casa $e$ dos filhos passaram a ser valores que os homens devem adotar $e$ as mulheres vêm valorizando $e$ demandando dos maridos/companheiros. Mudanças que têm seus pés fincados na entrada das mulheres destas classes no mercado de trabalho e que fazem parte do conjunto de predicados do novo homem. $\mathrm{O}$ próprio cuidado com a casa, com a decoração e a limpeza transmitiriam uma imagem positiva desse homem, associada à modernidade que as mulheres da sua classe social vêm buscando. Então, em lugar de fazer mal e amolecer o homem, a ideia de cuidar da casa é ressignificada como arma de sedução e de promoção profissional, uma forma de reforçar a masculinidade. No entanto, nas matérias dessa edição cuidar da casa não significa lavar e passar roupas, limpar o chão ou a geladeira, mas comprar vinhos, aparelhos tecnológicos, móveis e toda sorte de utensílios domésticos. Um "dono de casa" moderno, tecnológico e gastador, não um homem "trabalhador doméstico".

Os editoriais de abril, maio, junho e outubro, especialmente, apresentam um jogo retórico de valorização e desvalorização entre o leitor - sujeito que já assumiu a leitura da revista e está consciente de que as mudanças que ela propõe são realmente necessárias - e o não leitor, os "outros homens" que ainda não se deram conta dessa necessidade e ridicularizam os primeiros a partir, sobretudo, das mudanças que tratam da estética e do cuidado com o corpo, ou dos traços que os aproximam da feminilidade ou homossexualidade. Os editoriais vão no sentido contrário e constroem argumentos de valorização do homem que mudou usando expressões e palavras enaltecedoras e afinadas com a contemporaneidade: "antenado", "moderno", "inteligente", "exigente", "equilibrado", "qualificado", "público top". E outras que fazem parte do repertório simbólico da masculinidade: "prático", "sem medo", "mais seguros", "bem-sucedidos", "temos 
controle sobre nossa imagem", "macho de verdade". Assumir $e$ defender a ideia de que vaidade e cuidado com o corpo e a saúde são fundamentais para o homem moderno viver melhor significa enfrentar o "clube do bolinha universal", ou seja, demonstrar coragem, confirmar sua ousadia, pró-atividade, criatividade e masculinidade, nada a ver com ser menos masculino, muito pelo contrário.

Os desvalorizados aqui são os "outros" - os "brucutus", os "amigos mala", os "preconceituosos", "a tribo do tacape", os que estão "no bonde errado da história" -, pessoas que precisam ser ajudadas a encontrar o caminho. São desclassificados por compartilharem características que costumam ser valorizadas como tipicamente masculinas: pouca ou nenhuma vaidade, pouco cuidado com a saúde e com o corpo, pouca afinidade ou total desconhecimento sobre cuidados com a casa $e$ preparo de alimentos etc.

Os editoriais de abril e junho, apresentam um outro jogo retórico, igualmente interessante, entre disciplina/indisciplina $e$ equilíbrio/excesso. $\mathrm{O}$ homem contemporâneo sabe que precisa de disciplina para obter o que é fundamental: um corpo bonito $e$ saudável e conquistas profissionais e sexuais. E que os excessos, inclusive no que diz respeito ao exercício físico, não são convenientes. A indisciplina é uma marca dos "outros" que ainda não reconheceram as vantagens da mudança $e$ ainda estão ligados na ideologia "libertária" dos anos 1970 que se baseava na trilogia: "sexo, drogas e rock and roll". Ao homem do século XXI, prescrito pela Men's Health, serve a liberdade que o estado de bem-estar lhe confere, algo diametralmente oposto à ideia de satisfação daqueles anos.

$\mathrm{O}$ editorial de outubro, embora apresente marcas comuns ao editorial de abril, por exemplo, nos parece que mostra de forma emblemática o modelo de "novo homem" que a revista vem se esforçando em construir. Esse texto nos chamou a atenção especialmente para quatro ideias, ou marcas, bastante interessantes: a adoção das transformações propostas pela revista, sobretudo a vaidade e o cuidado com o corpo, é um movimento 
"natural", próprio da evolução dos homens; a forma como o editor tomou a ideia de crise da masculinidade, ou do masculino decorrente dos movimentos feministas, como sendo a causa do acirramento das fronteiras entre os gêneros e do "machismo", que levaram ao descuido com o corpo; a ideia de que os homens deram uma "resposta" infantil e pouco producente a esse movimento ao optar por acirrar o lado "brucutu" e o machismo, diferente do que propõe a revista; $e$ a explicitação de que foi a indústria de cosméticos que começou o movimento para incitar e incluir os homens entre consumidores destes produtos.

Reconhecer os dois primeiros fatores e compreender esse novo cenário, um sinal de que os homens mudaram e uma forma de olhar pra frente e "sem medo, como todo macho de verdade", é uma ideia que só foi explicitada nesse editorial, mas que atravessa todos os outros. A alusão ao mundo dos esportes esteve presente - jogada, taco - assim como a ideia de que os comportamentos humanos atuais podem ser ainda reflexos do que foi aprendido e impresso no nosso DNA nos tempos em que vivíamos em cavernas; uma ideia que se expressou a partir da palavra "tacape" (e, em outros editoriais, "caverna" e "brucutu").

O editorial busca romper por completo com a ideia de que são as mulheres e também os homossexuais que precisam usar cremes e outros produtos, falando de forma direta aos homens sobre os medos que precisam ser superados para que fiquem mais bonitos, saudáveis e modernos. Mas, ao mesmo tempo se desvincula do feminino quando afirma que "cuidar da beleza é uma jogada bem prática, portanto, masculina". O que não está dito, mas está presente no texto, é que as mulheres não são práticas, $e$, diferente do que a revista propóe aos homens, podem perder horas com beleza e ter uma nécessaire enorme. A "dica" de ter poucos $e$ bons produtos na sua nécessaire reforça a característica de praticidade e a oposição ao feminino, buscando a adesão dos leitores ao que é sugerido pela revista. É um discurso permeado pelas novas verdades sobre a masculinidade e que os homens que querem adotar as indicadas mudanças podem usar ao se "defender" dos "brucutus" que não têm uma nécessaire, $e$ 
que podem colocar em dúvida o que há de mais fundamental na masculinidade dominante: a heterossexualidade. Sendo o pouco cuidado com o corpo um dos valores da masculinidade que dificulta a compra desses produtos por boa parte da população masculina, essa insistência faz todo o sentido.

Nas Cartas de 2009 as marcas discursivas que destacamos nos editoriais de 2008 não estavam tão explícitas. Mas identificamos outras duas ideias bastante interessantes e que dizem igualmente respeito aos valores da nova masculinidade: equilibrio e estilo. Este último ponto atravessou especialmente o editorial de novembro de 2008 e, por isso, será trazido agora para a análise. Entre os editoriais de 2009, destacamos os de maio, outubro, novembro e fevereiro como exemplares da presença da ideia de "estilo". E os de janeiro, fevereiro e setembro como emblemáticos da presença da ideia de equilíbrio. $\mathrm{O}$ de agosto retoma a ideia de disciplina.

Mas tomaremos, primeiramente, o editorial de novembro de 2008. Nesse texto, temos explicitada já no título a ideia de que ser um novo homem significa ter estilo: "Tenha estilo, seja sincero". O texto começa comentando o perfil do filósofo francês BernardHenry Levy construído pelo jornal The New Yorker, em que o estilo de se vestir do filósofo foi o ponto destacado: "um cara conhecido por usar camisas brancas, sem gravata, abertas até o abdome tanque, bronzeado". Destaca ainda a observação feita pelo filósofo de que esse aspecto não é relevante em seu perfil $e$ que só usa esse tipo de roupa por praticidade. Em seguida, o editor constrói uma argumentação sobre a importância de se apresentar bem vestido e bem penteado:

Levy sabe que dar uma entrevista ao Times - ou ao setor de recrutamento de qualquer empresa - envolve regras de estilo. Elas podem pavimentar o caminho para suas ideias, tirar da frente eventuais rejeições e ganhar a confiança do interlocutor. Ou seja, a forma como você se veste e penteia os cabelos, a armação dos seus óculos, o tecido da sua camisa (ou como ela fica aberta sobre seu peito), a idade do seu relógio, tudo isso conspira para formar uma babel 
que vai impactar o interlocutor antes mesmo de você dizer 'olá, muito prazer, Bernard-Henry'.

No olho, lê-se "Valorize-se. Aí começa o seu sucesso".

Pode-se perceber a presença, mais uma vez, da supervalorização do trabalho ao sugerir que estar bem vestido pode significar ser bem recebido em uma entrevista profissional. Mas, o que queremos destacar é o jogo retórico construído a partir das palavras do filósofo sobre a pouca importância que deveria ser dada à sua "barriga tanquinho" $e$ às roupas que usou para a entrevista, $e$ as do ator Matthew McConaughey por ter admitido em uma entrevista à Men's Health norte-americana que se importa com o seu estilo, ou nas suas palavras destacadas no editorial: "o estilo é o resultado combinado de como um homem se coloca, o quanto ele vale e o que ele representa", palavras que poderiam ter sido escritas em qualquer editorial e edição da Men's Health. Nesse sentido, o filósofo é "bobo" ao não assumir que se importa com a aparência e com usar roupas modernas, ou não teria aquela barriga e não se vestiria daquele jeito, enquanto o ator é um homem moderno que assume que cuidar do corpo e da aparência é um aspecto importante. Uma falsa disputa entre um filósofo e um ator, pois ambos reforçam o estereótipo de masculinidade ditado pela revista, e, no final, a ideia que fica é a da "barriga tanquinho".

No editorial de outubro, intitulado "Não basta ser cool", o editor mostrou de forma muito clara sua concepção acerca do estilo do "novo homem" ao afirmar que o leitor sabe

que estilo é um conceito que vai além da fachada. Estilo é um conjunto de conhecimentos - cultura, bom gosto, vivência - do qual você lança mão na hora de se comunicar com o mundo (especialmente com as mulheres, vai). Vem dele até mesmo sua chamada beleza interior, o alto-astral, o bom humor.

Um estilo bem apurado pode impressionar a "colega lindona" e o "chefe". Afirma ainda que o guia de estilos da revista 
é o primeiro e até aquela data era o único no mercado. E termina dizendo que "sabemos que atrás de uma boa aparência deve sempre haver um cara legal, inteligente, divertido, maduro. Um não vive muito tempo na boa sem o outro". No olho, lê-se: "Forma e conteúdo devem caminhar juntos. A aparência é o cartão de visita de sua inteligência".

No editorial de novembro de 2009, o tema "estilo" volta a aparecer, juntamente com a agregação de certos valores à compra de roupas. O texto afirma que o leitor "pensa em estilo todo dia ao acordar - é uma característica natural do cara que busca, na mesma medida, bem-estar e sucesso."

sabe que sua relação com comprar roupa vai além do fato de cobrir as partes íntimas e regular a temperatura corporal. Comprar roupa para um cara como você tem a ver com o seu dinamismo, sua vontade de se divertir, de ganhar pontos na carreira, no sexo, no meio social.

No olho, lê-se: "Quer mudar o visual? Estamos aí. Quer manter o estilo? Também...".

Assim como nos editoriais de 2008, a supervalorização da aparência e a relação entre beleza, cuidado corporal e sucesso na vida profissional e sexual são flagrantes, sobretudo no editorial de outubro. Mas, diferentemente daqueles editoriais que tomaram bastante a retórica da desvalorização do antigo em proveito do novo, aqui há somente a valorização do novo, a partir do seu atrelamento a uma ideia cara na atualidade: a de estilo ou de se ter um estilo.

Ter um estilo ou "ser dono de um estilo" significa ter uma forma própria, ímpar, de se posicionar no mundo. Mas, do modo como está colocado nos editoriais, ter estilo tem relação direta com a aparência e, por consequência, com o consumo. Castro, citando Ganetz (1995), compreende estilo como um "contraponto ou equilíbrio entre a coletividade da moda e a personalidade individual, garantindo a possibilidade de cada um identificar-se com outros e ser único" (Castro, 2007:87), uma possibilidade que é 
dada pelo consumo. Podemos dizer então que o estilo pode ser compreendido como um traço da identidade dos sujeitos, sobretudo se concordarmos que o corpo tornou-se o local de estruturação da identidade.

Sem nos atermos a quaisquer teóricos/as, tomamos estilo na sociedade de consumo como sendo a organização de elementos de modo que formem um todo coerente e possam ser compreendidos como tal. Os estilos podem ser segmentados por faixa etária, localidade e classe social, por exemplo; englobam modos de vestir, comer, falar, comportar-se, lugares que se frequentam etc. E, mais uma vez, a mídia é um elemento fundamental, deflagrando, valorizando e/ou desvalorizando estilos.

Diferente do que se possa pensar, e apesar dos apelos à individualidade, a sociedade de consumo demanda a multiplicidade e a expansão de estilos que possibilitem uma margem maior de opções às quais os sujeitos possam se filiar. $\mathrm{E}$, entre eles, o estilo de vida jovem vem sendo muito valorizado ultimamente, pois trata-se de uma fase da vida á qual se associam vários valores positivos. Assim, esse estilo pode ser adotado em outras fases da vida para agregar valor a quem o porta (Castro, 2007). Ideia que se associa também aos apelos pela manutenção da beleza e do corpo jovem que temos percebido na mídia, e na Men's Health, de forma especial.

A ideia de "ter estilo" construída nos editoriais é o que vai afiliar o leitor a uma certa posição revelada por sua "classe" (que podemos tomar no sentido de classe social e elegância), por "seu estado de espírito" etc. Uma ideia que, além do que foi dito acima, agrega outros valores igualmente caros aos nossos tempos $e$ importantes para a masculinidade: individualidade, autonomia $e$ independência. Mas ter estilo pode, ao mesmo tempo, significar estar vinculado a uma rede à qual outros/as pertencem, com o mesmo estilo ou "com estilo". Essa ideia parece contraditória com relação à anterior, sobretudo se pensarmos que embora o editorial afirme que a revista respeita o estilo pessoal do leitor, o que ela faz é oferecer dicas e "receitas" de estilo para serem adotados pelos seus milhares de leitores, retirando a marca de individualidade. 
Mas se maximizarmos as qualidades desse grupo, se afirmarmos que seus membros são modernos, avançados, inteligentes, bem informados, corajosos - e além de tudo heterossexuais -, fazer parte dele e compartilhar do seu estilo torna-se algo bastante interessante. $\mathrm{E}$, nesse sentido, a ideia de estilo nos remete às concepções acerca do consumo referidas na primeira parte deste trabalho, sobretudo as de Douglas $e$ Isherwood (2009), uma vez que ter ou assumir um estilo significa filiar-se a um grupo, valorizar certas regras, distinguir-se socialmente. $\mathrm{O}$ estilo diz coisas sobre quem o assume e, ao demarcar posições sociais, precisa ser ratificado por certos grupos. Ambos os aspectos são relevantes na valorização do leitor da revista: se, por um lado, ele é independente, autônomo, "dono de um estilo próprio"; por outro, ele faz parte de um grupo de homens modernos $e$ "antenados" com o seu tempo, os homens que leem Men's Health. E que, ao mesmo tempo, são modernos e "antenados" porque são independentes e autônomos.

$\mathrm{O}$ editorial de novembro, além da ideia de estilo, alinha as ideias de fazer compras e divertir-se. $\mathrm{E}$ também associa o ato de comprar roupas a valores e desejos tipicamente tomados como masculinos, como o dinamismo e os ganhos na carreira, na vida sexual e social. Ao relacionar entre os resultados do ato de comprar roupas esses valores e desejos, o editor ressignifica um costume, tradicionalmente associado às mulheres, como sendo vantajoso e bem-vindo para os homens. Revela-se claramente a valorização do consumo, que, juntamente com os investimentos no corpo, atravessam toda a revista.

Tomando o que afirma Zygmund Bauman (2008), na sociedade de consumo, ou a que vivemos, as pessoas tornaram-se mercadorias vendáveis, sendo reconhecidas $e$ interpelados primeiramente como consumidores/as. É o consumo o que localiza a pessoa nessa sociedade, o que a torna sujeito, o que a inclui ou rechaça, valoriza ou desvaloriza, constituindo sua identidade, tornando o "consumir" um investimento na afiliação de si próprio à sociedade. No caso dos nossos textos, o sujeito 
interpelado deve alinhar-se ao modelo de homem moderno valorizado pela revista ao consumir novos produtos e serviços.

Sendo assim, uma revista como a $M H$ pode ser bem-vinda por atuar nos dois lados dessa moeda: servindo como promotora $e$ valorizadora do que o mercado produz, e como informante do que os sujeitos precisam adquirir (incluindo o corpo) ou descartar para terem prestígio nessa sociedade, constantemente se "autofabricando" para manterem-se valiosos/as e adequados/as. A revista é um lugar do encontro entre os/as que produzem $e$ os/as que consomem.

Outro ponto relevante desses editoriais é a presença da ideia de equilibrio, recomendado como a melhor forma de organizar o tempo $e$ as atividades, pois, para se obter uma vida mais longa $e$ satisfatória, não é aconselhável restringir o prazer - da comida, do sexo, da diversão -, mas encontrar o equilibrio entre tudo isso. No entanto, há hábitos a serem restringidos, como o uso de drogas ilícitas e o tabagismo.

Segundo o editorial de janeiro, há momentos na vida em que se deve "meter o pé na jaca, na porta, no balde e no acelerador" e outros de "meter o pé no freio". Uma vida equilibrada entre os excessos e as restrições é o caminho mais desejável e a Men's Health vai ajudar o homem nisso. O editorial de fevereiro reforça a concepção de equilibrio e volta à ideia de estilo relacionado à vida saudável:

Equilíbrio. Bem-estar. Qualidade de vida. É isso. Saúde e bem-estar são uma coisa só [...]. Nossa ideia é dar ferramentas para você equilibrar sexo, vinho, rock and roll, corpo sarado, comida boa, doce far nientem, estilo, foco $e$ sabedoria.

No olho se lê: "Viver com saúde é questão de estilo de vida".

Em setembro, tomando a ideia de que a crise econômica que abalava o mundo naquele período perdia o fôlego no Brasil, o editorial volta a tocar na ideia do equilibrio ao convocar os homens a aproveitarem os 120 dias que restam do ano. Para isso, 
a revista oferecia "dicas de decoração, sedução, encontros com a galera, nutrição, fitness e organização para elevar o espírito de quem gosta de viver bem, morar bem". Em seguida, afirma que o homem contemporâneo é o que está entre os que viveram o "espírito" de Woodstock, para os quais "o importante era o conforto espiritual", e os consumistas do começo da globalização, ou seja, homens dos extremos. Mas que "Agora é hora do equilibrio. De ter e de curtir [...]. A ideia é lembrar a você que olhar para si próprio tem a ver com algo mais do que com narcisismo - tem a ver com seu sucesso, sua sobrevivência".

As ideias de disciplina e controle voltaram nos editoriais de maio e agosto nos mesmos moldes do ano de 2008. Em agosto, o editorial intitulado "Estética e estatística" trata da barriga - perigos da gordura abdominal e ganhos com sua redução - e retoma a ideia de controle e disciplina. Afirma que "estar bem condicionado é uma ferramenta de marketing pessoal", pois ter um corpo bem cuidado, ou sem gordura abdominal, significa que o homem cuida da "sua casa por natureza", o que gera sobre ele uma expectativa positiva por parte do patrão e das mulheres, pois essa aparência indica que ele também é capaz de cuidar bem do emprego (ou casa do patrão) e de uma família (casa com uma mulher). Para se conseguir tudo isso é preciso monitoramento, "controle, equilíbrio, contenção...".

Mas o que queremos chamar a atenção no editorial de maio é a articulação entre esses dois valores - ter estilo e ser equilibrado - e o novo homem. No título "Aqui, agora. E amanhã" está explicitado qual é o estilo do homem Men's Health, e nele se fala de flexibilização, o que nos permite dizer que o objetivo não é a ruptura, mas uma flexibilização com relação ao antigo modelo de masculinidade. A ideia de flexibilização está presente nas discussões de Connell (2005) e de Mosse (1996), quando se referem às possibilidades de mudanças da masculinidade. Uma flexibilização que possibilita aos homens se adaptarem aos novos tempos, ao mundo pós-movimentos feministas e homossexuais, à sociedade de consumo, às novas demandas profissionais etc. Mas as flexibilizações sugeridas pela Men's Health dizem respeito aos 
cuidados com o corpo, à aparência, à sexualidade e, vez por outra, à saúde.

A gente vive dizendo que o principal eixo do cara moderno é o bem-estar [...] pense em equilíbrio. Flexibilidade. Organização. Disciplina [...] Nossa proposta é: organize a bagunça da sua vida e você vai passar a viver com mais intensidade. Não desperdice energia com o improviso, o imprevisto, o imponderável. Improviso é uma delícia, mas o prazer do planejamento é mais duradouro. O negócio é foco. No prazer e no trabalho [...]. Não privilegie o consumo (a marca mais badalada, a peça mais cara), mas a construção de um estilo (por meio do qual você comunica sua personalidade e sabedoria, sem se tornar vítima da moda). Estilo é uma ferramenta poderosa de conquista sexual e profissional.

Quanto ao equilibrio, o editorial elege as figuras do metrossexual e do yuppie como antagônicos ao novo homem, pelos excessos que representam: o primeiro, com relação à vaidade, e o segundo, ao trabalho. O novo homem é o signatário de equilíbrio e da disciplina, não dos excessos.

Como último ponto, desejamos retornar à insistente convocação dos leitores para tornarem-se homens modernos através do autocuidado e da construção de uma nova conformação corporal. Essa modernidade seria alcançada a partir do abandono dos padrões "brucutu" e da adoção de novos padrões de comportamento que visem o "aprimoramento" do corpo, sobretudo. O historiador da cultura George Mosse (1996), em estudo acerca da criação da imagem de masculinidade normativa na Europa no final do século XVIII, faz uma relação bastante interessante entre a construção das nações europeias naquele período e o modelo de masculinidade construído $e$ necessário para aquele momento. Um estereótipo masculino que conhecemos ainda hoje: um homem branco, heterossexual, ocidental, definido também pela dureza de caráter, autocontrole, coragem e pelo corpo musculoso e forte construído através de 
exercícios físicos e de grandes esforços. Um corpo capaz de demonstrar o que esse homem era interiormente. Esse estereótipo da masculinidade opunha-se ao de feminilidade que se apresentava naquele momento, e também atuava como definidor do contra-estereótipo, o marginalizado. Essas ideias ajudam-nos a argumentar que apesar do discurso de modernidade difundido pela Men's Health no que diz respeito ao corpo e alguns aspectos da masculinidade, o que a revista faz é reeditar um antigo modelo que tem por base as mesmas características que, no século XVIII, permitiam a alguns sujeitos incluírem-se no modelo de masculinidade e distanciarem-se do que era feminino e/ou homossexual.

\section{Conclusão}

Todos esses editoriais ratificam a ideia de que o homem da Men's Health é alguém que sabe que mudar na aparência não significa afeminar-se ou "tornar-se" homossexual, mas ser mais atraente para as mulheres e mais invejado e admirado pelos outros homens, o que o levará a fazer mais sexo e a conquistar uma carreira profissional de sucesso. Ser saudável, ser cuidadoso com a aparência, vestir-se bem e ter um corpo bonito são sinais de inteligência e chaves para o sucesso no século XXI. Esses atributos são alcançados pelo esforço pessoal, pela disciplina, organização do tempo e equilíbrio das atividades. Trata-se de promover o cuidado do corpo e da aparência, ou seja, o consumo de um certo corpo e de uma certa aparência, atividade tradicionalmente vinculada ao universo feminino, partindo dos valores mais centrais da masculinidade tradicional - ênfase na performance (hetero)sexual e foco no sucesso financeiro e profissional.

A insistência em sublinhar a necessária heterossexualidade desse "novo homem" nos parece revelar o grande risco corrido pelos leitores da revista: que o desejo pelo corpo masculino musculoso, jovem e bem torneado implique não apenas em desejo de consumo, isto é, em ser esse corpo, mas também no 
desejo homossexual de um outro corpo. Daí a reafirmação constante da mulher como alvo da cobiça e da conquista.

Neste final, voltamos às considerações de Michel Foucault acerca do poder. Segundo Foucault, a liberdade $e$ a "insubmissão" são inerentes às relações de poder. $\mathrm{E}$, nesse sentido, é preciso atentar para os confrontos, as resistências e as possibilidades de escapatória acessíveis aos sujeitos. Se os discursos de revistas como a Men's Health, apoiados na racionalidade da medicina e outras ciências do comportamento, fazem parte de uma ampla estratégia de poder em torno da transformação/manutenção das relações de gênero, os editoriais são campos de negociações com os homens, pois consideramos que os textos apresentam marcas indeléveis de negociação da masculinidade com os leitores, reforçando a todo o momento as vantagens que há na adoção das mudanças propostas, pois além de não colocarem em risco a masculinidade e o seu principal atributo - a heterossexualidade -, a fortalece.

\section{Referências bibliográficas}

AlmeIDA, Miguel Vale de. Senhores de si: uma interpretação antropológica da masculinidade. Lisboa, Fim de Século, 2000.

BAUMAN, Zygmund. Vida para o consumo: a transformação das pessoas em mercadoria. Rio de Janeiro, J. Zahar, 2008.

CAMPBELl, Colin. The Romantic Ethic and the spirit of modern consumerism. Oxford e Cambridge, Blackwell Publishers, 1995.

CASTRO, Ana Lúcia de. Culto ao corpo e sociedade: mídia, estilo de vida e cultura de consumo. São Paulo, Annablume/Fapesp, 2007.

CECChETTO, Fátima. A sina de ser forte: corpo, sexualidade e saúde entre lutadores de jiu-jítsu no Rio de Janeiro. In: HEILBORN, Maria Luiza et al. Sexualidade, reprodução e saúde. Rio de Janeiro, Editora FGV, 2009.

CONNELL, Robert W. Globalization, imperialism, and masculinities. In: KimMEL, M.; HeARN, J.; CONNELl, R. W. Handbook of studies on men \& masculinities. California, Sage, 2005, pp.71-90. 
. La organización social de la masculinidad. In: VALDÉZ, TERESA; OlivarRíA, José (Ed.). Masculinidad/es: poder y crisis. Santiago, FLACSO/Isis, Ed. de las Mujeres, 1997, pp.31-48.

. Políticas da masculinidade. Revista Educação e Realidade, vol. 20, nº 2, Porto Alegre, jul./dez., 1995, pp.185-206.

DOUGLAS, Mary; ISHERWOOD, Baron. O mundo dos bens: para uma antropologia do consumo. Rio de Janeiro, Ed. UFRJ, 2009.

FAUSTO-STERLING, Anne. Sexing the body: gender politics and the construction of sexuality. New York, Basic Books, 2001.

FouCAult, Michel. A arqueologia do saber. Rio de Janeiro, Forense Universitária, 2007.

. O sujeito e o Poder. In: DREYFUS, Herbert L. Michel Foucault, uma trajetória filosófica: para além do estruturalismo e da hermenêutica. Rio de Janeiro, Forense Universitária, 1995, pp.231-249.

FRAGA, Alex Branco. Exercício da informação: governo dos corpos no mercado da vida ativa. Tese de Doutorado, Faculdade de Educação, Universidade Federal do Rio Grande do Sul, Porto Alegre, 2005.

GANETZ, $\mathrm{H}$. The shop, the home and feminity as a masquerade. In: FORNAS, J.; BOLIN, G. (Ed.). Youth culture a late modernity. Londres, Sage, 1995, pp.72-99.

GoldENBERG, Mirian. De perto ninguém é normal. Rio de Janeiro, Record, 2005.

HeILBORN, Maria Luiza; CARRARA, Sérgio. Em cena, os homens. Revista Estudos Feministas, vol. 6, 1998, pp.370-374.

; GOUVEIA, Patrícia Fernanda. "Marido é tudo igual": mulheres populares e sexualidade no contexto da Aids. In: PARKER, RICHARD; BARBOSA, REGINA. Sexualidades pelo avesso: direitos, identidades e poder. Rio de Janeiro, IMS/UERJ; São Paulo, Ed. 34, 1999, pp.175-198.

HUBBARD, Ruth. The politics of women's biology. Rutgers University Press, 1990.

KIMMEL, Michael. Homofobia, temor, vergüenza y silencio en la identidad masculina. In: VALDÉS, TERESA; OlIVARIA, José (Ed.). Masculinidade/s: 
poder y crisis. Santiago, FLACSO/Isis, Ed. de las Mujeres, 1997, pp.49-62.

A produção simultânea de masculinidades hegemônicas $e$ subalternas. Horizontes Antropológicos: Corpo, Doença e Saúde, vol. 4, no 9, out. 1998, pp.103-117.

MARSHALL, B. The new virility: Viagra, male aging and sexual function. Sexualities, vol. 9, n 3, 2006, pp.345-362.

MOSSE, George L. The image of man: the creation of modern masculinity. New York, Oxford Univ. Press, 1996.

NOLASCO, Sócrates Alveres. De Tarzan a Homer Simpson: banalização e violência masculina em sociedades contemporâneas ocidentais. Rio de Janeiro, Rocco, 2001.

PALmA, Alexandre. Exercício físico e saúde; sedentarismo e doença: epidemia, causalidade e moralidade. Motriz - Revista de Educação Física, vol. 15, no 1, Rio Claro-SP, jan./mar. 2009, pp.185-191.

SCHIEBINGER, Londa. "Skeletons in the closet: The first illustrations of female skeleton in Eighteenth-Century Anatomy". In: GALLAGHER, C. (Ed.). Making of the modern body. Berkeley, Univ. of California Press, 1987, pp.42-82.

THOMPSON, John B. A mídia e a modernidade: uma teoria social da mídia. Petrópolis-RJ, Vozes, 2002.

VerISSIMO, Jorge. O corpo na publicidade. Lisboa, Colibri/Instituto Politécnico de Lisboa, 2008. 